\title{
Foreign Body in The Small Intestine
}

Benjamin Creelan, $M D$

\section{Case Presentation}

This adult was working on a ladder during a home restoration project. She placed the bit in her mouth while changing the screwdriver bit, then fell from the ladder and inadvertently swallowed the bit. In the emergency room, her review of systems and laboratories were unremarkable. Imaging revealed the bit to be within the duodenal lumen and after four days of serial $\mathrm{x}$ rays, the bit was retrieved by snare colonoscopy at the ileocecal junction. The patient remained asymptomatic and had no complications.

\section{Discussion}

Although most ingested foreign bodies will pass through the gastrointestinal system unaided, $10-20 \%$ may require endoscopic intervention, and less than $1 \%$ will require surgery. ${ }^{1}$, ${ }^{2}$ Erosion, obstruction, and perforation are more likely to occur at regions with sharp angles or narrowing, particularly the upper esophageal sphincter and ileocecal junction. ${ }^{3}$ Endoscopic retrieval of foreign bodies should be employed for any object that has failed to pass through the esophagus after 24 hours due to the high risk of perforation. ${ }^{3,4}$ Fever, vomiting, or abdominal pain demands a prompt surgical consultation. If endoscopic retrieval is unsuccessful, laparoscopy may be employed. ${ }^{5}$ Snare or forceps endoscopy should be avoided in cases where rupture of the foreign body may be fatal, such as in concealed colonic narcotic packets, a practice called "body packing."1,6

\section{References}

1. Ginsberg, G. Management of ingested foreign objects and food bolus impactions. Gastro Endosc 1995; 41:33-38

2. Conway, W.C., Sugawa, C., Ono, H., et al. Upper GI foreign body: An adult urban emergency hospital experience. Surg Endosc 2007; 21:455-60.

3. Eisen, G.M., Baron, T.H., Dominitz, J.A.., et al. Guideline for the management of ingested foreign bodies. Gastro Endosc 2002; 55:802-6.

4. Simic MA, Budakov BM. Fatal upper esophageal hemorrhage caused by a previously ingested chicken bone: case report. Am J Forensic Med Pathol 1998;19:166-8.

5. Chin EH, Hazzan D, Herron DM. Laparoscopic removal of intraabdominal foreign bodies. Surg Endosc 2007; 21:1457.

6. Lancashire MJR, Legg PK, Lowe M, et al. Surgical aspects of international drug smuggling. Br Med J 1988; 296:1035-7.

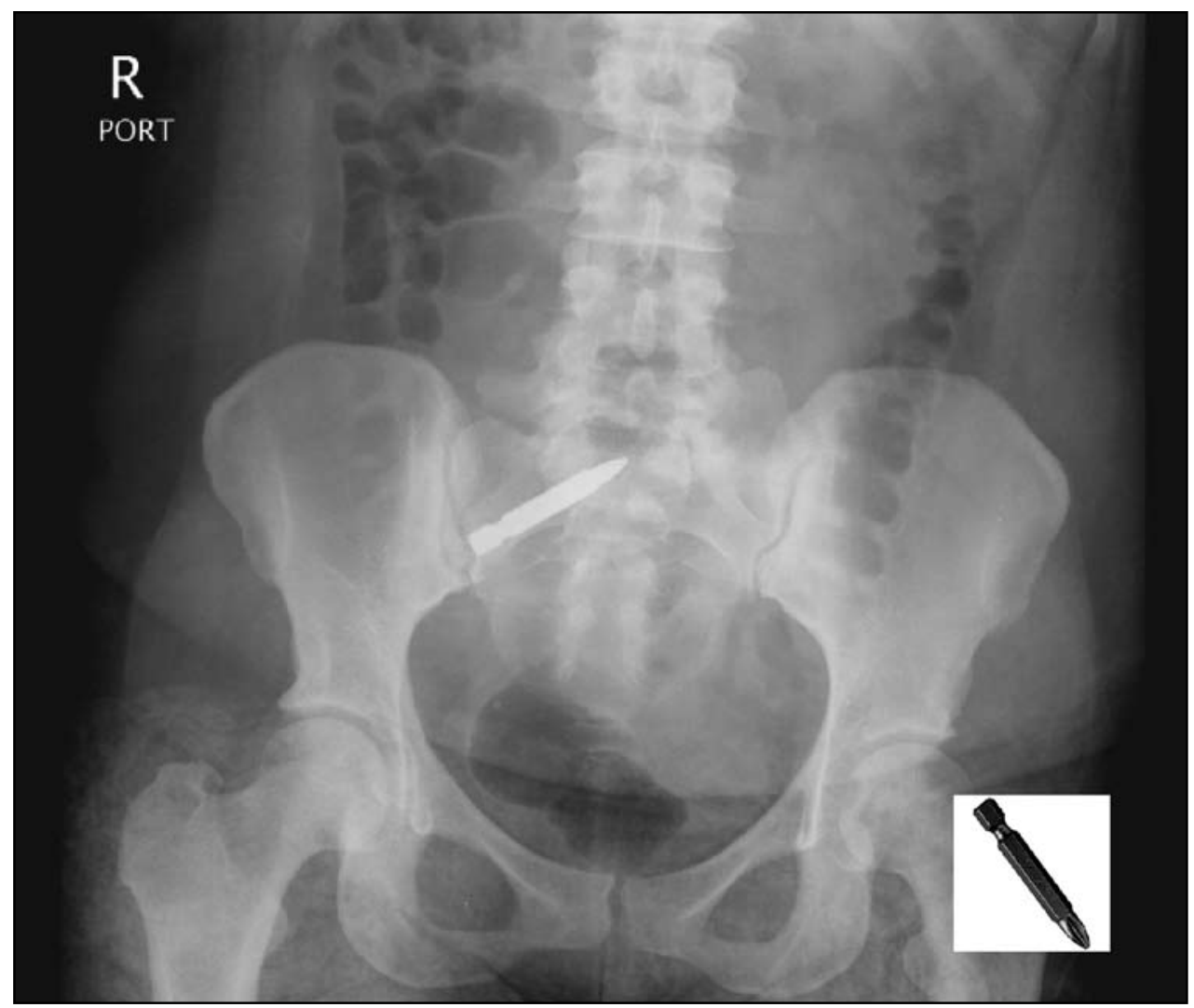

